\title{
Four lanthanide-carboxylate coordination polymers with mixed 2,3-naphthalenedicarboxylate and phen ligands: Syntheses, structures, luminescent and magnetic properties
}

\author{
Min $\mathrm{Hu}^{\text {a }}$, Hui Zhao ${ }^{\text {a }}$, E. Carolina Sañudo ${ }^{\mathrm{b}}$, Min Chen ${ }^{\mathrm{a}, \Uparrow}$ \\ ${ }^{a}$ Henan Provincial Key Laboratory of Surface \& Interface Science, Zhengzhou, Henan 450002, PR China \\ ${ }^{\mathrm{b}}$ Departament de Quimica Inorgànica i Institut de Nanociència i Nanotecnologia, Universitat de Barcelona, Diagonal 645, 08028 Barcelona, Spain
}

\section{a r t i 1 e i n fo}

Article history:

Received 30 April 2015

Accepted 10 August 2015

Available online 29 August 2015

Keywords:

Lanthanide-carboxylate coordination

polymers

2,3-Naphthalenedicarboxylate

Crystal structures

Luminescence

Magnetic properties

\begin{abstract}
a b s t r a c t
Four new lanthanide-carboxylate coordination polymers of the formula $\left[\mathrm{Ln}_{3} \mathrm{~L}_{4}(\mathrm{phen})_{4}\left(\mathrm{H}_{2} \mathrm{O}\right)_{4}\right]\left(\mathrm{ClO}_{4}\right)-$ $2 \mathrm{H}_{2} \mathrm{O}$, (Ln = Dy (1), Tb (2), Ho (3) and Er (4), L = 2,3-naphthalenedicarboxylate and phen = 1,10-phenanthroline) were solvothermally synthesized. Their structures as well as magnetic and photoluminescent properties were completely investigated. Complexes $1-4$ are isostructural and exhibit 1D ribbon-like chains with envelope-like sixteen-membered rings. The $\mathrm{Dy}^{\mathrm{III}}$ and $\mathrm{Tb}^{\mathrm{III}}$ complexes show the corresponding characteristic luminescence in the visible region and the $\mathrm{Er}^{\mathrm{III}}$ complex shows luminescence in the nearinfrared region upon excitation with UV rays. Studies on the magnetic properties are reported. The Dy(III) analog complex 1 exhibits slow magnetic relaxation and could be a new example of a Dy(III) SMM (single molecule magnet).
\end{abstract}

\section{Introduction}

The design and construction of lanthanide coordination polymers (LCPs) is attracting increasing attention not only due to their desirable structural features [1-2], but also due to their exceptional optical [3] and magnetic properties [4] arising from $4 \mathrm{f}$ electrons. So far, many LCPs have been prepared and their use in practical applications has been widely investigated [5]. However, designing a practical method for synthesizing LCPs with predictable and controlled geometries still remains challenging, due to the high and variable coordination numbers and the flexible coordination environments of the lanthanide ions [6]. As is known, rare earth ions have a high affinity for hard donor atoms and ligands containing oxygen or hybrid oxygen-nitrogen atoms, especially multi-carboxylate ligands, which are usually employed in the construction of LCPs with unique structures and useful properties [7]. Among the versatile multi-carboxylate complexes, aromatic benzene- and naphthalene-based derivatives, such as benzenedicarboxyl (1,4- [8], 1,3- [9], or 1,2- [10]), 1,3,5-benzenetricarboxyl [11], 1,2,4,5-benzenetetracarboxyl [12], 1,2,3,4,5,6-benzenehexacarboxyl [13], naphthalenedicarboxyl $(1,4-[14]$ or $2,6-[15])$ and 1,4,5,8-naphthalenetetracarboxyl [16], have been extensively used

\footnotetext{
$\Uparrow$ Corresponding author.

E-mail address: humin@zzuli.edu.cn (M. Chen).
}

in the preparation of a variety of lanthanide-carboxylate coordination polymers owing to their reliable and rich coordination modes.

Despite the remarkable achievements in this aspect [8-16], however, to predict and further accurately control the framework array of a given crystalline product still remain a considerable challenge at this stage. This mainly arises from the fact that the subtle assembly progress may be influenced by many intrinsic and external parameters, such as the auxiliary co-ligands [17], solvent [18], counter-anion [19], temperature [20], $\mathrm{pH}$ value of the solution [21] and so on, which determine the formation of different thermodynamically favored crystalline products. For instance, the introduction of 1,10-phenanthroline chelating reagents [22] as auxiliary co-ligands into lanthanide-carboxyl reaction systems leads to the formation of interesting coordination architectures. In this context, 2,3-naphthalenedicarboxylate (L), with an extended $\mathrm{p}$-conjugated system as an analogous but bulky derivative of 1,2-benzenedicarboxylate $\left(\mathrm{H}_{2} \mathrm{BDC}\right)$, has virtually not been noticed to fabricated LCPs to date. In our group, we have constructed a series of transition metal complexes ( $\mathrm{Zn}(\mathrm{II}), \mathrm{Cd}(\mathrm{II}), \mathrm{Ag}$ (I), $\mathrm{Cu}(\mathrm{II})$ and $\mathrm{Ni}(\mathrm{II})$ ), which exhibit diverse structures from discrete tetranuclear species to $3 \mathrm{D}$ networks with luminescent or magnetic properties [17a,b,23].

As an extension of the work mentioned above, as well as to better understand the nature of the luminescence in the structures of lanthanide multi-carboxylates, we present herein the syntheses, structures, photoluminescence and magnetic properties of four 
lanthanide-carboxylate coordination polymers based on $\mathrm{H}_{2} \mathrm{~L}$ and phen ligands. It was hoped that the combination of two types of ligands would enhance the energy-transfer efficiency from the ligand to the lanthanide ions. Meanwhile, utilization of heavy lanthanide ions such as Dy(III) and Ho(III) has also become more popular in the design and synthesis of SMMs due to their larger angular moment and strong magnetic anisotropy in ground multiple states [24].

\section{Experimental}

\subsection{Materials and general methods}

All reagents and solvents for the syntheses were commercially available and used as received. Elemental analyses (C, H and $\mathrm{N}$ ) were performed on a Vario EL III Elementar analyzer. The IR spectra were recorded in the range $4000-400 \mathrm{~cm}^{-1}$ on a Tensor 27 OPUS (Bruker) FT-IR spectrometer with $\mathrm{KBr}$ pellets. The emission spectra in the visible region were tested on an F-7000 (HITACHI) spectrophotometer and those in the near-infrared region were measured on an FLS-980 fluorescence spectrophotometer.

\subsection{Synthesis of complexes 1-4}

All four complexes were prepared under similar methods. A general synthetic procedure is described as follows, using Dy ${ }^{\mathrm{III}}$ complex 1 as an example. A solution of 2,3-naphthalenedicarboxylic acid $\left(\mathrm{H}_{2} \mathrm{~L}\right)(10.8 \mathrm{mg}, 0.05 \mathrm{mmol}), 1,10$-phenanthroline (phen) monohydrate $(9.0 \mathrm{mg}, 0.05 \mathrm{mmol})$ and $\mathrm{NaOH}(4 \mathrm{mg}$,

$0.1 \mathrm{mmol})$ in $\mathrm{CH}_{3} \mathrm{OH}(10 \mathrm{~mL})$ was carefully layered on top of a $\mathrm{H}_{2} \mathrm{O}$ solution $(15 \mathrm{~mL})$ of $\mathrm{Dy}\left(\mathrm{ClO}_{4}\right)_{3} 6 \mathrm{H}_{2} \mathrm{O}(56.9 \mathrm{mg}, 0.1 \mathrm{mmol})$ in a test tube. Colorless block single crystals suitable for X-ray analysis appeared at the tube wall after ca. three weeks at room temperature.

$\left[\mathrm{Dy}_{3} \mathrm{~L}_{4}(\text { phen })_{4}\left(\mathrm{H}_{2} \mathrm{O}\right)_{4}\right]\left(\mathrm{ClO}_{4}\right)-2 \mathrm{H}_{2} \mathrm{O}$ (1): Yield: $0.017 \mathrm{~g}(60.5 \%$ based on $\mathrm{H}_{2} \mathrm{~L}$ ). Elemental Anal. Calc. for $\mathrm{C}_{96} \mathrm{H}_{68} \mathrm{ClDy}_{3} \mathrm{~N}_{8} \mathrm{O}_{26}$ : C, 50.74; H, 3.02; N, 4.93. Found: C, 50.31; H, 3.27; N, 4.79\%. IR $\left(\mathrm{KBr}, \mathrm{cm}^{-1}\right)$ : $3443 \mathrm{br}, 1615$ vs $1558 \mathrm{~s}, 1464 \mathrm{~m}, 1405$ vs $1348 \mathrm{~m}$, $1094 \mathrm{~s}, 891 \mathrm{w}, 864 \mathrm{w}, 842 \mathrm{w}, 824 \mathrm{~m}, 771 \mathrm{~m}, 725 \mathrm{~m}, 622 \mathrm{w}, 583$ $\mathrm{m}, 556 \mathrm{w}, 481 \mathrm{w}$.

$\left[\mathrm{Tb}_{3} \mathrm{~L}_{4}(\text { phen })_{4}\left(\mathrm{H}_{2} \mathrm{O}\right)_{4}\right]\left(\mathrm{ClO}_{4}\right)-2 \mathrm{H}_{2} \mathrm{O}$ (2): Yield: $0.019 \mathrm{~g} \quad(68.2 \%$ based on $\mathrm{H}_{2} \mathrm{~L}$ ). Elemental Anal. Calc. for $\mathrm{C}_{96} \mathrm{H}_{68} \mathrm{ClN}_{8} \mathrm{O}_{26} \mathrm{~Tb}_{3}$ : C, 50.98; H, 3.03; N, 4.95. Found: C, 50.81; H, 3.20; N, 4.80\%. IR $\left(\mathrm{KBr}, \mathrm{cm}^{-1}\right)$ : $3444 \mathrm{br}, 1615$ vs $1551 \mathrm{~s}, 1463 \mathrm{~m}, 1404$ vs $1347 \mathrm{~m}$, 1093 s, 890 w, 864 w, 842 w, 824 m, 771 m, 726 m, 623 w, 583 $\mathrm{m}, 557 \mathrm{w}, 482 \mathrm{w}$.

$\left[\mathrm{Ho}_{3} \mathrm{~L}_{4}(\text { phen })_{4}\left(\mathrm{H}_{2} \mathrm{O}\right)_{4}\right]\left(\mathrm{ClO}_{4}\right)-2 \mathrm{H}_{2} \mathrm{O}$ (3): Yield: $0.022 \mathrm{~g} \quad(76.5 \%$ based on $\mathrm{H}_{2} \mathrm{~L}$ ). Elemental Anal. Calc. for $\mathrm{C}_{96} \mathrm{H}_{68} \mathrm{ClHo}_{3} \mathrm{~N}_{8} \mathrm{O}_{26}$ : C, 50.58; H, 3.01; N, 4.91. Found: C, 50.31; H, 3.28; N, 4.69\%. IR $\left(\mathrm{KBr}, \mathrm{cm}^{-1}\right): 3443 \mathrm{br}, 1614 \mathrm{~s}, 1551 \mathrm{~s}, 1464 \mathrm{~m}, 1405 \mathrm{~s}, 1348 \mathrm{~m}$, $1095 \mathrm{~s}, 893 \mathrm{w}, 864 \mathrm{w}, 845 \mathrm{w}, 823 \mathrm{~m}, 771 \mathrm{~m}, 726 \mathrm{~m}, 640 \mathrm{w}, 585$ $\mathrm{w}, 558 \mathrm{w}, 481 \mathrm{w}$.

$\left[\mathrm{Er}_{3} \mathrm{~L}_{4}(\text { phen })_{4}\left(\mathrm{H}_{2} \mathrm{O}\right)_{4}\right]\left(\mathrm{ClO}_{4}\right)-2 \mathrm{H}_{2} \mathrm{O}$ (4): Yield: $0.023 \mathrm{~g} \quad(80.6 \%$ based on $\mathrm{H}_{2} \mathrm{~L}$ ). Elemental Anal. Calc. for $\mathrm{C}_{96} \mathrm{H}_{68} \mathrm{ClEr}_{3} \mathrm{~N}_{8} \mathrm{O}_{26}$ : C, 50.42; H, 3.00; N, 4.90. Found: C, 50.21; H, 3.18; N, 4.84\%. IR $\left(\mathrm{KBr}, \mathrm{cm}^{-1}\right): 3445 \mathrm{br}, 1615 \mathrm{~s}, 1551 \mathrm{~s}, 1464 \mathrm{~m}, 1404 \mathrm{~s}, 1347 \mathrm{~m}$, 1095 s, 892 w, 844 m, 823 w, 770 w, 725 m, 640 w, 584 w, 481 w.

Caution: Although no problem was encountered in this study, perchlorate complexes are potentially explosive and should be handled with the proper precautions!

\subsection{X-ray crystallographic studies of complexes 1-4}

X-ray single-crystal diffraction data for complexes 1-4 were collected on an Agilent diffractometer at ambient temperature with Mo Ka radiation $(k=0.71073 \AA)$. There was no evidence of crystal decay during the data collection. The program saINT [28] was used for integration of the diffraction profiles and a semi-empirical absorption correction was applied using the SADABS program [29]. All the structures were solved by direct methods using the SHELXS program of the SHELXTL package and refined by full-matrix least-squares methods with SHELXL [30]. The final refinements were performed by full-matrix least-squares methods with anisotropic thermal parameters for all non-H atoms on $F^{2}$. The C-bound hydrogen atoms were generated with the assigned isotropic thermal parameters, and those of water molecules were first located in the difference electron density map and then placed in their calculated positions with fixed thermal factors. The disordered $\mathrm{ClO}_{4}^{-}$ anion was restrained in order to obtain reasonable thermal parameters. Crystallographic data and structural refinement details for complexes 1-4 are summarized in Table 1, and selected bond lengths and angles are shown in Tables S1-S4.

\subsection{Magnetic measurements}

Magnetic measurements were carried out at the Unitat de Mesures Magnètiques (Universitat de Barcelona) on polycrystalline samples (circa $30 \mathrm{mg}$ ) with a Quantum Design SQUID MPMS-XL magnetometer equipped with a $5 \mathrm{~T}$ magnet. Diamagnetic corrections were calculated using Pascal's constants and an experimental correction for the sample holder was applied.

\section{Results and discussion}

\subsection{Descriptions of the crystal structures for complexes 1-4}

Single crystal X-ray diffraction analyses revealed that complexes 1-4 are isostructural and crystallize in the tetragonal system, $P 4 / n c c$ space group (see Tables 1 and $\mathrm{S} 1-\mathrm{S} 4$ in Supplementary material). Thus, complex 1 , as a representative example, is selected to describe the crystal structure in details. As depicted in Fig. 1a, the asymmetric unit contains one and a half occupied Dy ${ }^{I I I}$ cations, one deprotonated L ligand, one phen ligand and one coordinated water molecule, as well as one free perchlorate anion and half a free water molecule, exhibiting a butterfly-like configuration. There are two categories of Dy ${ }^{\mathrm{III}}$ ions in the unit and both kinds of Dy ${ }^{\text {III }}$ ions are octa-coordinated, exhibiting a slightly distorted square antiprismatic geometry, but with different coordination environments. The Dy 1 ion is coordinated by four carboxylate oxygen atoms from four different $\mathrm{L}$ ligands and four oxygen atoms from terminal water molecules to give a $\mathrm{Dy}_{1} \mathrm{O}_{8}$ sphere. In contrast, the Dy2 ion is surrounded by four carboxylate oxygen atoms from two different $\mathrm{L}$ ligands and four pyridine nitrogen atoms from two phen ligands to give a $\mathrm{Dy}_{2} \mathrm{O}_{4} \mathrm{~N}_{4}$ sphere. The distances of the Dy-O $\left[\mathrm{Dy}-\mathrm{O}_{\text {carboxylate }}=2.285(7)-2.323(6), \mathrm{Dy}-\mathrm{O}_{\text {hydroxyl }}=2.430(5) \AA\right]$ and Dy $-\mathrm{N}[\mathrm{Dy}-\mathrm{N}=2.531(7)-2.542(9) \AA]$ bonds are comparable to the reported Dy ${ }^{\mathrm{III}}$ complexes [24c].

It is noteworthy that the carboxylic group of the L ligand adopts two different coordination modes (see Fig. S1). The carboxylic group [O1 and O2] of the L ligand is bound in the $\mathbf{I}_{1}-\mathbf{g}^{1}: \mathbf{g}^{0}$ monodentate mode to coordinate the Dy 2 ion. However, the other carboxylic groups [O3 and O4] of the L ligand adopt the $\mathbf{I}_{2}-\mathbf{g}^{1}: \mathbf{g}^{1}$-syn, anti-bis-(bridging) bidentate mode to bridge adjacent Dy 1 and Dy 2 ions and simultaneously to form a dinuclear unit with a Dy-Dy separation of 5.9249(1) A. Every two dinuclear segments are further grafted to form an envelope-like sixteen-membered ring, which is defined by the atoms Dy1, O4, C2, O3, Dy2, O3A, C2A, O4A, Dy1B, O4B, C2B, O3B, Dy2C, O3C, C2C, O4C and leads to intrachain Dy-- -Dy distances of 7.8757(3) $\AA$ (see Fig. 1b) (Symmetry code: $\mathrm{A}=-x+1,-y+1,-z+3 / 2 ; \mathrm{B}=x-1 / 2, y+1 / 2,-z+3 / 2$; 
Table 1

Crystallographic data and structure refinement summary for complexes $1-4$. $^{\text {a }}$

\begin{tabular}{|c|c|c|c|c|}
\hline & 1 & 2 & 3 & 4 \\
\hline Chemical formula & $\mathrm{C}_{96} \mathrm{H}_{68} \mathrm{ClDy}_{3} \mathrm{~N}_{8} \mathrm{O}_{26}$ & $\mathrm{C}_{96} \mathrm{H}_{68} \mathrm{ClN}_{8} \mathrm{O}_{26} \mathrm{~Tb}_{3}$ & $\mathrm{C}_{96} \mathrm{H}_{68} \mathrm{ClHo}{ }_{3} \mathrm{~N}_{8} \mathrm{O}_{26}$ & $\mathrm{C}_{96} \mathrm{H}_{68} \mathrm{ClEr}_{3} \mathrm{~N}_{8} \mathrm{O}_{26}$ \\
\hline Formula mass & 2272.53 & 2261.79 & 2279.82 & 2286.81 \\
\hline Crystal system & tetragonal & tetragonal & tetragonal & tetragonal \\
\hline Space group & $P 4 / n c c$ & $P 4 / n c c$ & $P 4 / n c c$ & $P 4 / n c c$ \\
\hline$a(\AA)$ & $23.5008(5)$ & $23.5008(5)$ & $23.5076(7)$ & $23.5008(5)$ \\
\hline$b(\AA)$ & $23.5008(5)$ & $23.5008(5)$ & $23.5076(7)$ & $23.5008(5)$ \\
\hline$c(\AA)$ & $15.7514(7)$ & $15.7514(7)$ & $15.7312(6)$ & $15.7514(7)$ \\
\hline$V\left(\AA^{3}\right)$ & $8699.3(5)$ & $8699.3(5)$ & $8693.2(5)$ & $8699.3(5)$ \\
\hline$T(\mathrm{~K})$ & $294(2)$ & 294(2) & $294(2)$ & $294(2)$ \\
\hline$Z$ & 4 & 4 & 4 & 4 \\
\hline$/\left(\mathrm{mm}^{-1}\right)$ & 2.671 & 2.530 & 2.822 & 2.985 \\
\hline$R_{\text {int }}$ & 0.0576 & 0.0748 & 0.0544 & 0.0997 \\
\hline${ }^{\mathrm{a}} R_{1}(I>2 r(I))$ & 0.0529 & 0.0954 & 0.1392 & 0.0993 \\
\hline${ }^{\mathrm{b}} w R_{2}$ (all data) & 0.1154 & 0.2066 & 0.2648 & 0.2236 \\
\hline GOF & 1.147 & 1.320 & 1.336 & 1.118 \\
\hline $\mathrm{D} q_{\text {maximum, minimum }}\left(\mathrm{e} \AA^{-3}\right)$ & $1.237,-0.743$ & $1.292,-0.849$ & $2.189,-0.971$ & $1.303,-1.129$ \\
\hline
\end{tabular}

${ }^{\mathrm{a}} R_{1}=\mathrm{R}\left(|| F_{\mathrm{o}}|-| F_{\mathrm{c}}||\right) / \mathrm{R}\left|F_{\mathrm{o}}\right|$.

${ }^{\mathrm{b}} w R_{2}=\left[\mathrm{R} w\left(\left|F_{\mathrm{o}}\right|^{2}-\left|F_{\mathrm{c}}\right|^{2}\right)^{2} / \mathrm{R} w\left(F^{2}\right)^{2}\right]^{1 / 2}$.

$\mathrm{C}=x+3 / 2, y+1 / 2, z$.). Two neighboring rings possessing two different directions form a dihedral angle of $58.26^{\circ}$ and such connectivity is repeated periodically, forming $1 \mathrm{D}$ chain (see Fig. 1c).

In this work, we selected 2,3-naphthalenedicarboxylate, an ana$\log$ of 1,2 BDC, as the main ligand and phen as an assistant ligand. In all types of carboxylic acids, benzenedicarboxylates are widely used in the construction of coordination polymers due to their capability of acting as bridging ligands in various coordination modes [31]. Owing to their larger radii, Ln(III) ions have higher coordination numbers than transition metal ions, and thus the BDC anions tend to adopt varied coordination modes to coordinate with $\mathrm{Ln}(\mathrm{III})$ ions to saturate their coordination sites. The results indicate that different substitution positions of the two carboxyl groups on the benzene ring take an important role in the formation of different structures. So, as expected, 1,2-BDC is not as good as 1,4-BDC and 1,3-BDC for constructing 3-D networks. To the best of our knowledge, 3-D crystal structures containing 1,2-BDC as a link are rarely reported [32], while 1-D chains and 2-D layer structures containing it are commonly encountered in the references. On the other hand, one phen molecule occupies two coordination sites by adopting the chelating mode, which may lead to lower dimensionality of coordination polymers. However, phen can also construct supramolecular architectures with higher dimensional structures by forming $\mathrm{C}-\mathrm{H}---\mathrm{O}$ hydrogen bonds and $\mathrm{p}-\mathrm{-} \mathrm{p}$ aromatic interactions. For example, as reported by $\mathrm{Lu}$ [33], 3-D networks of $\left[\mathrm{Yb}_{2}(1,2-\mathrm{BDC})_{3}(\text { phen })\left(\mathrm{H}_{2} \mathrm{O}\right)_{2}\right]_{n}-3.5 n \mathrm{H}_{2} \mathrm{O}$ are formed via hydrogen bonds and/or $\mathrm{p}$-- -p interactions connecting 1-D chains. 2,3-Naphthalenedicarboxylate (L), with an extended p-conjugated system, is an analogous but bulky derivative of 1,2-BDC and has a bigger space resistance; thus it is difficult to construct high-dimensional networks for lanthanides with this ligand. Thus four 1-D isostructural lanthanide-carboxylate complexes were constructed in this work. Notably, neither hydrogen bonding nor $p--p$ interactions can be found interchain or intrachain in complexes $1-4$.

\subsection{PXRD analysis and IR spectra for complexes 1-4}

The purity and homogeneity of the bulk products of complexes 1-4 were determined by comparison of the simulated and experimental X-ray powder diffraction patterns. The peak positions of the experimental patterns for complexes 1-4 (see Fig. S2) nearly match with the corresponding simulated ones generated from single crystal X-ray diffraction data, although some minor Bragg peak positions are shifted in comparison to the simulated ones. The IR spectra of complexes 1-4 closely resemble each other (Fig. S3).
The peaks around $3444 \mathrm{~cm}^{-1}$ are ascribed to the $\mathrm{O}-\mathrm{H}$ stretching vibration, suggesting the presence of water molecules. The strong vibrations of carboxylate groups appeared at around $1615 \mathrm{~cm}^{-1}$ for asymmetric stretching and $1404 \mathrm{~cm}^{-1}$ for symmetric stretching. The absence of a band at around $1650-1700 \mathrm{~cm}^{-1}$ indicates the deprotonation of $\mathrm{COOH}$ to generate the $\mathrm{COO}-$ anion coordination to the metal ions. The IR spectra shows a very strong band around $1094 \mathrm{~cm}^{-1}$, indicating the presence of the $\mathrm{ClO}_{4}^{-}$anion in the resulting complexes.

\subsection{Photoluminescent properties of complexes 1, 2 and 4}

Because LCPs are used as functional probes in biological systems and have a range of applications in lasers, sensors, electroluminescence displays and light emitting diodes, [34] the study of the fluorescence of $\mathrm{Ln}$ complexes with aromatic ligands has attracted great interest. The emission spectra of solid samples for complexes 1 and 2 were determined at an excitation wavelength of $305 \mathrm{~nm}$ under ambient temperature. Fortunately, the two com- plexes both displayed their characteristic emissions. The character- istic emissions of the Dy(III) ion in complex 1 are shown in Fig. 2a. Two peaks at 467 and $630 \mathrm{~nm}$ are assigned to the transitions ${ }^{4} \mathrm{~F}_{9 / 2}$ ? ${ }^{6} \mathrm{H}_{15 / 2}$ and ${ }^{4} \mathrm{~F}_{9 / 2}$ ? ${ }^{6} \mathrm{H}_{13 / 2}$ [3b], respectively. Fig. $2 \mathrm{~b}$ shows the emitting spectrum of the $\mathrm{Tb}$ (III) ion in complex 2 . The four peaks at $489,545,587$ and $616 \mathrm{~nm}$ are assigned to the transitions ${ }^{5} \mathrm{D}_{4}$ to ${ }^{7} \mathrm{~F}_{J}(J=6,5,4,3)[3 \mathrm{a}]$. The most intense emission of the ${ }^{5} \mathrm{D}_{4} ?{ }^{7} \mathrm{~F}_{5}$ transition at $545 \mathrm{~nm}$ is responsible for the green luminescence observed in 2. The intensities of ${ }^{5} \mathrm{D}_{4} ?{ }^{7} \mathrm{~F}_{J}(J=6,4,3)$ are lower than that of ${ }^{5} \mathrm{D}_{4} ?{ }^{7} \mathrm{~F}_{5}$, as observed in many $\mathrm{Tb}^{\mathrm{III}}$ containing complexes [25a]. Furthermore, the intensities of the two complexes based on the $\mathrm{H}_{2} \mathrm{~L}$ ligand are very weak, possibly due to the coordinated water molecules which reduce the luminescent intensity of the rare earth ions [35], and the energy transfer from the $\mathrm{H}_{2} \mathrm{~L}$ ligand to the lan- thanide(III) ions is inefficient from the theory of energy transfer [36]. The photoluminescence of the complex with ErIII ions in the near-infrared region was also tested on excitation with UV rays. The Er(III) complex displays an emission band at $1544 \mathrm{~nm}$ under the excitation at $300 \mathrm{~nm}$ (Fig. 2c), and it should be attributed to the transition ${ }^{4} \mathrm{I}_{13 / 2} ?{ }^{4} \mathrm{I}_{15 / 2}[25]$.

\subsection{Magnetic properties}

Magnetic susceptibility data were collected at applied dc fields of 0.02 and $0.3 \mathrm{~T}$ on a crushed crystalline sample between 2 and 


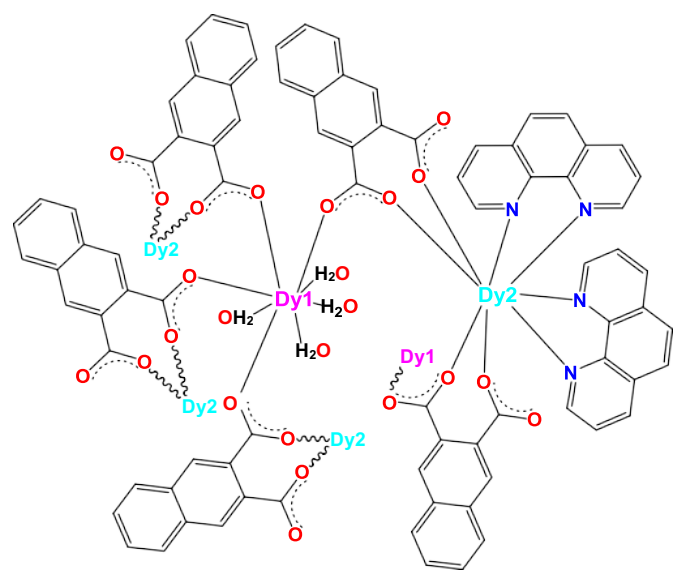

(a)

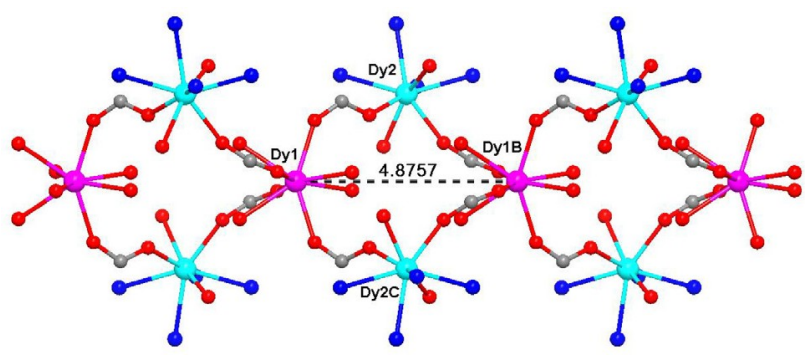

(b)

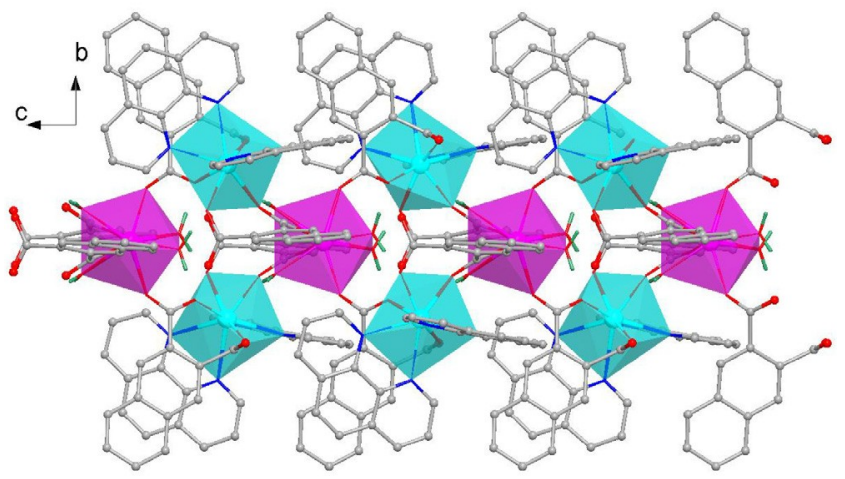

(c)

Fig. 1. Crystal structure of complex 1. (a) View of the coordination environment of the eight-coordinated Dy $\mathrm{DII}^{\mathrm{III}}$ ion. (b) The rings formed from carboxylate bridging resulting in one intrachain Dy-- -Dy distances. (c) The polyhedron view of the 1D chain along the $c$ axis. Some of the hydrogen atoms are omitted for clarity.

$300 \mathrm{~K}$. The data are shown in Fig. $3 \mathrm{a}$ as a $V T$ vs $T$ plot. The susceptibility is not field dependent. For complex 1 , the $V T$ product has a value of $44 \mathrm{~cm}^{3} \mathrm{~K} \mathrm{~mol}^{-1}$ at $300 \mathrm{~K}$, in agreement with the expected value of $43 \mathrm{~cm}^{3} \mathrm{~K} \mathrm{~mol}^{-1}$ for three non-interacting Dy (III) ions $\left({ }^{6} \mathrm{H}_{15 / 2}, S=5 / 2, L=5, J=15 / 2\right.$ and $\left.g_{J}=4 / 3\right)$ [26]. In the case of complex 2 , the value at $300 \mathrm{~K}$ is $37.2 \mathrm{~cm}^{3} \mathrm{~K} \mathrm{~mol}^{-1}$, as expected (35.43 $\mathrm{cm}^{3} \mathrm{~K} \mathrm{~mol}^{-1}$ for three isolated $\mathrm{Tb}(\mathrm{III})$ ion; ${ }^{7} \mathrm{~F}_{6}, S=3, L=3$, $J=6$ and $g_{J}=3 / 2$ ). At $300 \mathrm{~K}$ the $V T$ product has a value of $43.2 \mathrm{~cm}^{3} \mathrm{~K} \mathrm{~mol}^{-1}$ for complex 3, in agreement with the value for three Ho(III) ions with strong spin orbit-coupling $\left(14 \mathrm{~cm}^{3} \mathrm{~K} \mathrm{~mol}^{-1}\right.$ is the expected value for one isolated $\mathrm{Ho}(\mathrm{III})$ ion with ${ }^{5} \mathrm{I}_{8}, S=2$, $L=6, J=8$ and $\left.g_{J}=10 / 8\right)$. With regard to complex 4 , the $V T$ product has a value of $34.8 \mathrm{~cm}^{3} \mathrm{~K} \mathrm{~mol}^{-1}$, also in agreement with the expected value of $35.43 \mathrm{~cm}^{3} \mathrm{~K} \mathrm{~mol}^{-1}$ for three isolated $\operatorname{Er}(\mathrm{III})$ ions $\left({ }^{4} \mathrm{I}_{15 / 2}, S=3 / 2, L=6, J=15 / 2\right.$ and $\left.g_{J}=6 / 5\right)$. In the 1D structure, the lanthanide ions that form the repeating unit are very far away form

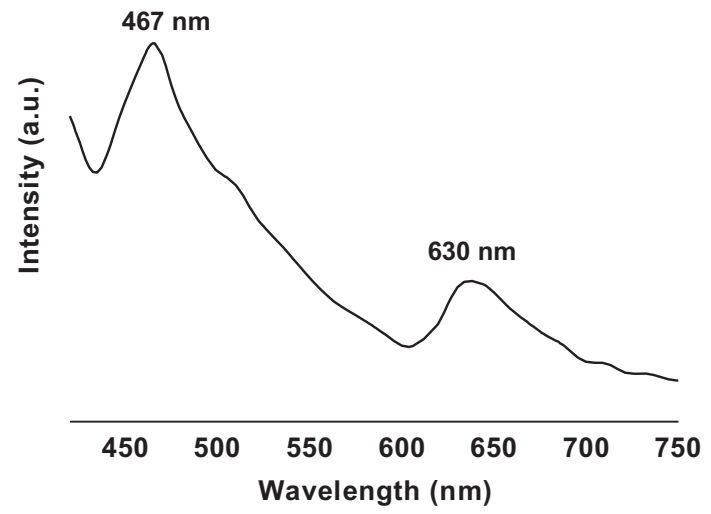

(a)

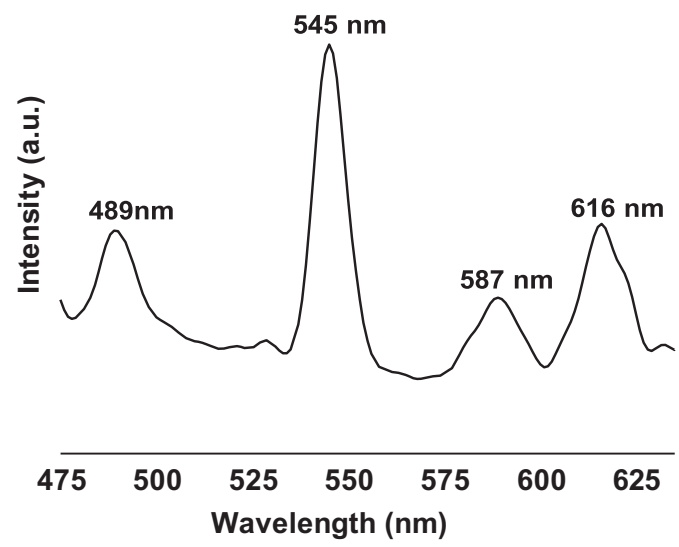

(b)

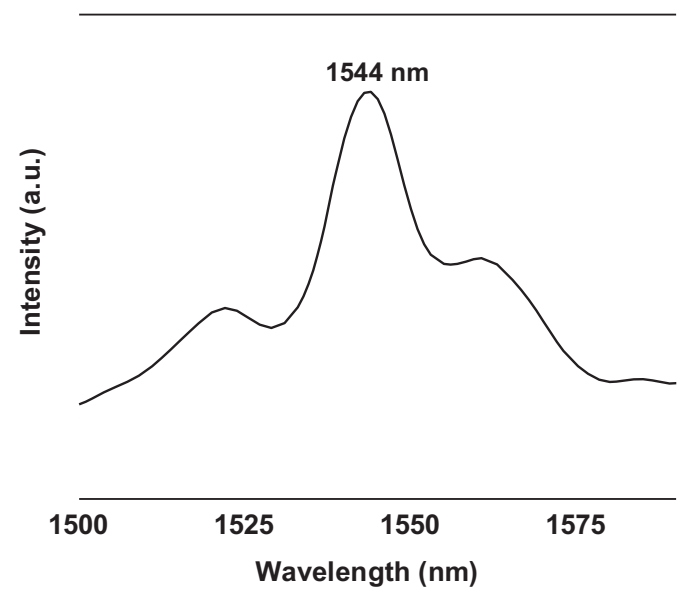

(c)

Fig. 2. Emission spectra of complexes 1 (a), 2 (b) and 4 (c).

each other, at about $6 \AA$, only being connected by syn, anti-carboxylato bridges, thus the magnetic coupling between them is negligible. As the temperature decreases, depopulation of the stark sublevels of complexes 1-4 is observed. For example, for complex 1 , when the temperature decreases so does the $V T$ product, until below $50 \mathrm{~K}$ where a sharp decrease to a $V T$ value of $28 \mathrm{~cm}^{3} \mathrm{~K} \mathrm{~mol}^{-1}$ is observed, indicating the depopulation of the excited Stark sublevels. The exchange interaction between the Dy(III) centers in 


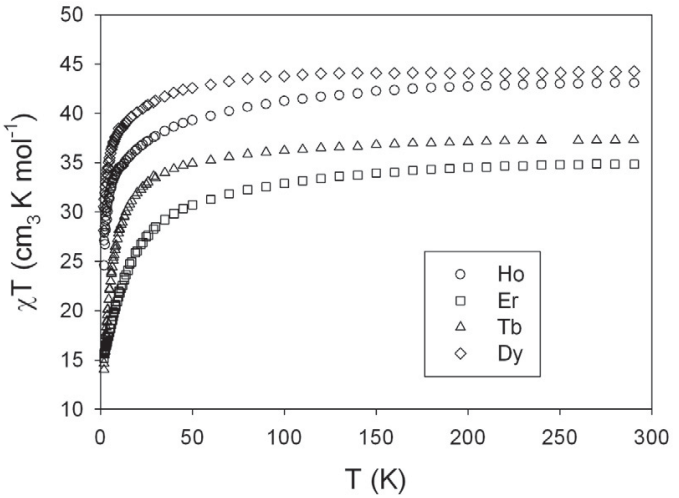

(a)

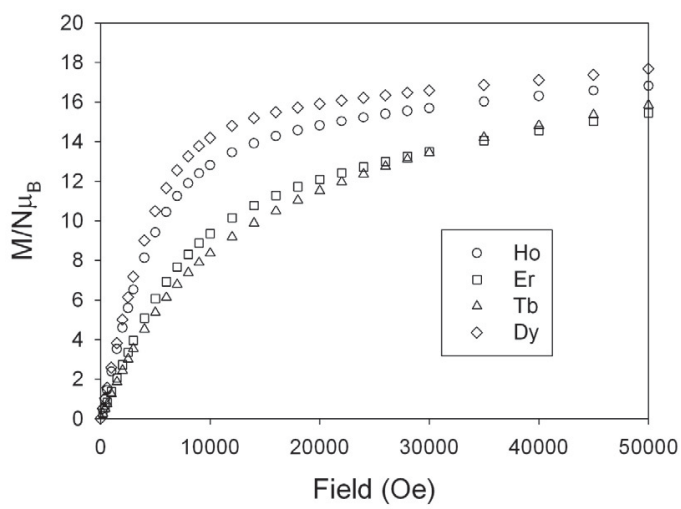

(b)

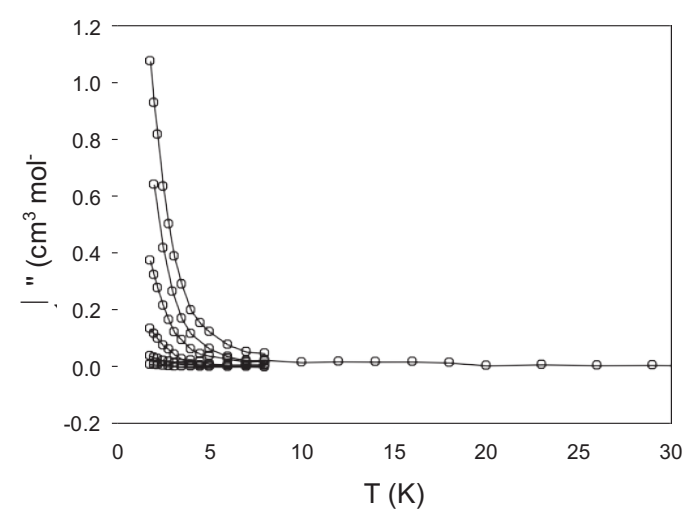

(c)

Fig. 3. (a) $V T$ vs. $T$ plots for complexes $1-4$ at 0.02 and $0.3 \mathrm{~T}$. (b) Magnetization vs. field plots for complexes 1-4 at $2 \mathrm{~K}$. (c) Out-of-phase ac magnetic susceptibility for complex 1 . The solid lines are only a guide for the eye.

complex 1 must be very weak, and the behavior of the coordination polymer resembles that of isolated Dy(III) ions.

The magnetization vs field was studied at $2 \mathrm{~K}$ and the results are shown in Fig. 3b. The magnetization shows a rapid increase at low fields and eventually reaches $17 \mathrm{IB}$ at $2 \mathrm{~K}$ and $5 \mathrm{~T}$ for complex 1 . This value is lower than the expected saturation value of 30 IB (for three Dy(III) ions), most likely due to anisotropy and important crystal-field effects [27] at the Dy(III) ion that eliminates the 16 -fold degeneracy of the ${ }^{6} \mathrm{H}_{15 / 2}$ ground state. Given the importance of developing new multifunctional materials with optical and magnetic properties [37-39], the lanthanides where chosen because they can display SMM behavior in the right crystal field and are luminescent. According to Rinehardt and Long [40], for the Dy(III) ion the right environment for SMM behavior is a 'sandwich' type ligand environment, with ligands on top and below the Dy(III) ion, and such is the coordination observed in complex 1. In order to check the behavior as a SMM, ac magnetic susceptibility data were collected at different frequencies for all species, but only complex 1 showed an out-of-phase signal [41]. The ac magnetic susceptibility data of complex 1 were collected and the out-of-phase signal is shown in Fig. 3c. Clearly, the tail of an out-of-phase peak is observed. The SMM behavior is reflected in frequency dependent peaks in the out-of-phase ac magnetic susceptibility [42]. However, in the particular case of complex 1, only the tail of the peak is observed. The appearance of ac outof-phase magnetic susceptibility peaks that are not frequency dependent can also be attributed to long-range order, however the weak magnetic interactions between the metallic centers expected from the crystal structure and the dc magnetic data of the complexes does not support this explanation. The ac magnetic susceptibility was collected at several frequencies between 1 and $1500 \mathrm{~Hz}$. No maxima were observed down to $1.8 \mathrm{~K}$. There is a strong dependence on the intensity of the out-of-phase signal and the frequency, suggesting that complex 1 can be a new example of a Dy(III) SMM.

\section{Conclusions}

In summary, we have successfully assembled four 1D lanthanide-carboxylate coordination polymers based on $\mathrm{H}_{2} \mathrm{~L}$ and phen ligands by using a solvothermal reaction method. The polymers of Dy ${ }^{\mathrm{III}}$ and $\mathrm{Tb}^{\mathrm{III}}$ show strong luminescence in the visible region on excitation and that of Er ${ }^{\text {III }}$ displays its characteristic luminescence in the near-infrared region. Studies of the magnetic properties are reported. The Dy(III) analog complex 1 exhibits slow magnetic relaxation and could be a new example of a Dy(III) SMM. The complexes reported here are thus new examples of multifunctional materials, and in particular complex 1, a luminescent SMM.

\section{Acknowledgements}

This work was supported by the National Natural Science Foundation of China (Grant Nos. 21171151 and 21201154) and financial support from the Spanish Government (Grant CTQ2012-32247).

\section{Appendix A. Supplementary data}

CCDC 1060783-1060786 contains the supplementary crystallographic data for complexes $1-4$. These data can be obtained free of charge via http://www.ccdc.cam.ac.uk/conts/retrieving.html, or from the Cambridge Crystallographic Data Centre, 12 Union Road, Cambridge CB2 1EZ, UK; fax: +44 1223336 033; or e-mail: deposit@ccdc.cam.ac.uk.

Supplementary data associated with this article can be found, in the online version, athttp://dx.doi.org/10.1016/j.poly.2015.08.030.

\section{References}

[1] (a) K. Binnemans, Chem. Rev. 109 (2009) 4283;

(b) L. Sorace, C. Benelli, D. Gatteschi, Chem. Soc. Rev. 40 (2011) 3092;

(c) M. Du, C.-P. Li, C.-S. Liu, S.-M. Fang, Coord. Chem. Rev. 257 (2013) 1282.

[2] (a) X.-Q. Zhao, X.-H. Liu, J.-J. Lia, B. Zhao, CrystEngComm 15 (2013) 3308; (b) L.-N. Jia, L. Hou, L. Wei, X.-J. Jing, B. Liu, Y.-Y. Wang, Q.-Z. Shi, Cryst. Growth Des. 13 (2013) 1570;

(c) J.-G. Duan, M. Higuchi, R. Krishna, T. Kiyonaga, Y. Tsutsumi, Y. Sato, Y. Kubota, M. Takata, S. Kitagawa, Chem. Sci. 5 (2014) 660.

[3] (a) Z.-J. Lin, L.-W. Han, D.-S. Wu, Y.-B. Huang, R. Cao, Cryst. Growth Des. 13 (2013) 255 ;

(b) P.-F. Shi, Z. Chen, G. Xiong, B. Shen, J.-Z. Sun, P. Cheng, B. Zhao, Cryst. Growth Des. 12 (2012) 5203;

(c) X. Wang, Q.-G. Zhai, S.-N. Li, Y.-C. Jiang, M.-C. Hu, Cryst. Growth Des. 14 (2014) 177 
[4] (a) Y. Li, J.-W. Yu, Z.-Y. Liu, E.-C. Yang, X.-J. Zhao, Inorg. Chem. 54 (2015) 153; (b) N.W. Waggoner, B. Saccoccia, I.A. Ibarra, V.M. Lynch, P.T. Wood, S.M. Humphrey, Inorg. Chem. 53 (2014) 12674;

(c) M. Chen, E.C. Sañudo, E. Jiménez, S.-M. Fang, C.-S. Liu, M. Du, Inorg. Chem. 53 (2014) 6708.

[5] (a) D.I. Alexandropoulos, A. Fournet, L. Cunha-Silva, A.M. Mowson, V. Bekiari, G. Christou, T.C. Stamatatos, Inorg. Chem. 53 (2014) 5420;

(b) M. Du, M. Chen, X. Wang, J. Wen, X.-G. Yang, S.-M. Fang, C.-S. Liu, Inorg. Chem. 53 (2014) 7074;

(c) D.C. Schmitt, N. Haldolaarachchige, J. Prestigiacomo, A. Karki, D.P. Young, S. Stadler, R. Jin, J.Y. Chan, J. Am. Chem. Soc. 135 (2013) 2748.

[6] (a) J.C.G. Bünzli, C. Piguet, Chem. Rev. 102 (2002) 1897;

(b) B. Moulton, M.J. Zaworotko, Chem. Rev. 101 (2001) 1629;

(c) L.-X. You, S.-J. Wang, G. Xiong, F. Ding, K.W. Meert, D. Poelman, P.F. Smet, B.-Y. Ren, Y.-W. Tian, Y.-G. Sun, Dalton Trans. 43 (2014) 17385.

[7] (a) P.I. Girginova, L.C.J. Pereira, J.T. Coutinho, I.C. Santos, M. Almeida, Dalton Trans. 43 (2014) 1897;

(b) L.-R. Guo, X.-L. Tang, Z.-H. Ju, K.-M. Zhang, H.-E. Jiang, W.-S. Liu, CrystEngComm 15 (2013) 9020.

[8] (a) Q.-Y. Liu, H.-Y. Cao, Y.-L. Wang, L.-L. Chen, Y. Liu, Inorg. Chim. Acta 414 (2014) 226;

(b) Z. Min, M.A. Singh-Wilmot, C.L. Cahill, M. Andrews, R. Taylor, Eur. J. Inorg. Chem. (2012) 4419.

[9] (a) Y. Wei, Q. Li, R. Sa, K. Wu, Chem. Commun. 50 (2014) 1820;

(b) H. Zhang, L. Zhou, J. Wei, Z. Li, P. Lin, S. Du, J. Mater. Chem. 22 (2012) 21210

[10] (a) W.-D. Song, J.-Bin Yan, H. Wang, L.-L. Ji, D.-Y. Ma, S.W. Ng, J. Coord. Chem. $63(2010) 625$;

(b) Z. Wang, Y.-H. Xing, C.-G. Wang, L.-X. Sun, J. Zhang, M.-F. Ge, S.-Y. Niu, CrystEngComm 12 (2010) 762.

[11] (a) Q. Zhou, F. Yang, B. Xin, G. Zeng, X. Zhou, K. Liu, D. Ma, G. Li, Z. Shi, S. Feng, Chem. Commun. 49 (2013) 8244; (b) K. Davies, S.A. Bourne, C.L. Oliver, Cryst. Growth Des. 12 (2012) 1999.

[12] (a) Laura Cañadillas-Delgado, Jorge Pasán, Oscar Fabelo, Miguel Julve, Francesc Lloret, Catalina Ruiz-Pérez, Polyhedron 52 (2013) 321; (b) P. Díaz-Gallifa, O. Fabelo, L. Cañadillas-Delgado, J. Pasán, A. Labrador, F. Lloret, M. Julve, C. Ruiz-Pérez, Cryst. Growth Des. 13 (2013) 4735.

[13] (a) Y. Han, L. Fu, L. Mafra, F.-N. Shi, J. Solid State Chem. 186 (2012) 165; (b) K.M.L. Taylor, A. Jin, W. Lin, Angew. Chem., Int. Ed. 47 (2008) 7722.

[14] (a) J. Yang, Q. Yue, G.-D. Li, J.-J. Cao, G.-H. Li, J.-S. Chen, Inorg. Chem. 45 (2006) 2857 ;

(b) B. Tan, Z.-L. Xie, M.-L. Feng, B. Hu, Z.-F. Wu, X.-Y. Huang, Dalton Trans. 41 (2012) 10576 .

[15] (a) D.-C. Hou, G.-Y. Jiang, Z. Zhao, J. Zhang, Inorg. Chem. Commun. 29 (2013) 148 ;

(b) I. Rodrigues, I. Mihalcea, C. Volkringer, T. Loiseau, M. Visseaux, Inorg. Chem. 51 (2012) 483;

(c) X. Zheng, C. Sun, S. Lu, F. Liao, S. Gao, L. Jin, Eur. J. Inorg. Chem. (2004) 3262

[16] (a) Y. Zheng, M. Camara, C. Daiguebonne, O. Guillou, K. Bernot, G. Calvez, F. Le Dret, N. Kerbellec, Inorg. Chim. Acta 401 (2013) 11; (b) N. Kerbellec, C. Daiguebonne, K. Bernot, O. Guillou, X. Le Guillou, J. Alloys Compd. 451 (2008) 377.

[17] (a) J. Wen, J.-Y. Hu, E.C. Sañudo, M. Chen, C.-S. Liu, Aust. J. Chem. 66 (2013) 963; (b) S.-M. Fang, Q. Zhang, M. Hu, X.-G. Yang, L.-M. Zhou, M. Du, C.-S. Liu, Cryst. Growth Des. $10(2010) 4773$.

[18] (a) S. Bhattacharya, A.J. Bhattacharyya, S. Natarajan, Inorg. Chem. 54 (2015) 1254 ;

(b) X. Chen, A.M. Plonka, D. Banerjee, J.B. Parise, Cryst. Growth Des. 13 (2013) 326

[19] (a) M. Du, C.-P. Li, J.H. Guo, CrystEngComm 11 (2009) 1536; (b) D.-M. Chen, X.-Z. Ma, X.-J. Zhang, N. Xu, P. Cheng, Inorg. Chem. 54 (2015) 2976.
[20] (a) M.K. Sharma, P.K. Bharadwaj, Inorg. Chem. 50 (2011) 1889; (b) J.A.K. Howard, H.A. Sparkes, CrystEngComm 10 (2008) 502

[21] (a) S.-M. Fang, Q. Zhang, M. Hu, E.C. Sañudo, M. Du, C.-S. Liu, Inorg. Chem. 49 (2010) 9617 ;

(b) L.-S. Long, CrystEngComm 12 (2010) 1354

[22] (a) S. Leininger, B. Olenyuk, P.J. Stang, Chem. Rev. 100 (2000) 853; (b) B.-H. Ye, M.-L. Tong, X.-M. Chen, Coord. Chem. Rev. 249 (2005) 545.

[23] (a) S.-M. Fang, M. Hu, Q. Zhang, M. Du, C.-S. Liu, Dalton Trans. 40 (2011) 4527

(b) M. Hu, Q. Zhang, Z. Kristallogr.-New Cryst. Struct. 225 (2010) 155.

[24] (a) V. Chandrasekhar, S. Hossain, S. Das, S. Biswas, J.-P. Sutter, Inorg. Chem. 52 (2013) 6346;

(b) Y.-X. Ren, X.-J. Zheng, L.-C. Li, D.-Q. Yuan, M. An, L.-P. Jin, Inorg. Chem. 53 (2014) 12234;

(c) J.-M. Zhou, W. Shi, N. Xu, P. Cheng, Cryst. Growth Des. 13 (2013) 1218.

[25] (a) H.-S. Wang, B. Zhao, B. Zhai, W. Shi, P. Cheng, D.-Z. Liao, S.-P. Yan, Cryst. Growth Des. 12 (2012) 2602;

(b) B. Li, W. Gu, L.Z. Zhang, J. Qu, Z.P. Ma, X. Liu, D.Z. Liao, Inorg. Chem. 45 (2006) 10425;

(c) L.N. Sun, J.B. Yu, G.L. Zheng, Eur. J. Inorg. Chem. (2006) 3962.

[26] C. Benelli, D. Gatteschi, Chem. Rev. 102 (2002) 2369.

[27] M.A. AlDamen, J.M. Clemente-Juan, E. Coronado, C. Martí-Gastaldo, A. GaitaArinño, J. Am. Chem. Soc. 130 (2008) 8874.

[28] SAINT Software Reference Manual, Bruker AXS, Madison, WI, 1998.

[29] G.M. Sheldrick, SADABS, Siemens Area Detector Absorption Corrected Software, University of Göttingen, Germany, 1996.

[30] G.M. Sheldrick, shelXtL NT Version 5.1. Program for Solution and Refinement of Crystal Structures, University of Göttingen, Germany, 1997.

[31] (a) Y.-S. Song, B. Yan, Inorg. Chim. Acta 358 (2005) 191;

(b) A. Thirumurugan, S. Natarajan, J. Mater. Chem. 15 (2005) 4588;

(c) Y.-H. Wan, L.-P. Jin, K.-Z. Wang, J. Mol. Struct. 649 (2003) 85;

(d) I. Mihalcea, C. Volkringer, N. Henry, T. Loiseau, Inorg. Chem. 51 (2012) 9610.

[32] P. Lightfoot, A. Snedden, J. Chem. Soc., Dalton Trans. (1999) 3549.

[33] Y. Wan, L. Zhang, L. Jin, S. Gao, S. Lu, Inorg. Chem. 42 (2003) 4985.

[34] (a) V. Mishra, H.J. Mishra, Phys. Chem. B 112 (2008) 4213;

(b) G.F. de Sá, O.L. Malta, C.D. Donega, A.M. Simas, R.L. Longo, P.A. Santa-Cruz, E.F. da Silva, Coord. Chem. Rev. 196 (2000) 165;

(c) S. Yanagida, Y. Hasegawa, K. Murakoshi, Y. Wada, N. Nakashima, T. Yamanaka, Coord. Chem. Rev. 171 (1998) 461;

(d) Y.-B. Lu, F.-M. Jian, S. Jin, J.-W. Zhao, Y.-R. Xie, G.-T. Luo, Cryst. Growth Des. 14 (2014) 1684.

[35] J. Xia, B. Zhao, H.-S. Wang, W. Shi, Y. Ma, H.-B. Song, P. Cheng, D.-Z. Liao, S.-P. Yan, Inorg. Chem. 46 (2007) 3450.

[36] (a) D.L. Dexter, J. Chem. Phys. 21 (1953) 836;

(b) D.-P. Dong, L. Liu, Z.-G. Sun, C.-Q. Jiao, Z.-M. Liu, C. Li, Y.-Y. Zhu, K. Chen, C.L. Wang, Cryst. Growth Des. 11 (2011) 5346;

(c) Y. Gai, F. Jiang, L. Chen, M. Wu, K. Su, J. Pan, X. Wan, M. Hong, Cryst. Growth Des. 14 (2014) 1010

[37] M.J. Ojea, D. Reta Mañeru, L. Rosado, J. Rubio Zuazo, G.R. Castro, S. Tewary, G. Aromí, G. Rajaraman, E. Jiménez, E.C. Sañudo, M. José, H. Ojea, R. Mañeru, R. Zuazo, R. German, C. Sañudo, Chemistry (2014) 10439.

[38] C.-S. Liu, M. Du, E.C. Sañudo, J. Echeverria, M. Hu, Q. Zhang, L.-M. Zhou, S.-M. Fang, E.C. Sanudo, Dalton Trans. 40 (2011) 9366.

[39] M. Menelaou, F. Ouharrou, L. Rodríguez, O. Roubeau, S.J. Teat, N. AliagaAlcalde, Chemistry 18 (2012) 11545.

[40] J.D. Rinehart, J.R. Long, Chem. Sci. 2 (2011) 2078.

[41] D.N. Woodruff, R.E.P. Winpenny, R.A. Layfield, Chem. Rev. 113 (2013) 5110.

[42] L. RosadoPiquer, E.C. Sañudo, Dalton Trans. 44 (2015) 8771. 